\title{
Análise entoacional na Amazônia: um estudo comparativo interdialetal das variedades do português falado em Mocajuba e Cametá (PA)
}

\section{Entoacional analysis in the Amazon: an acoustic study in Portuguese spoken in Mocajuba and Cametá (PA)}

Maria Sebastiana da Silva Costa https://orcid.org/0000-0001-7918-1972

Regina Célia Fernandes Cruz $^{2}$ https://orcid.org/0000-0003-3985-1024

Resumo: Este trabalho compreende um estudo comparativo das descrições prosódicas prévias sobre as variedades de Mocajuba e Cametá (PA) no seio do projeto AMPER-POR (COSTA, em andamento). Visa-se à descrição do comportamento entoacional de sentenças nas modalidades declarativa neutra e interrogativa total. Os parâmetros acústicos de frequência fundamental (doravante F0),

\footnotetext{
${ }^{1}$ Universidade Federal do Pará. E-mail: msebastcosta@gmail.com

${ }^{2}$ Universidade Federal do Pará / CNPq. E-mail: reginafcruz@gmail.com
} 
duração e intensidade foram foco de análise. Os procedimentos metodológicos adotados foram previamente estabelecidos pelo projeto AMPER-POR (CRUZ et al., 2012). Os movimentos melódicos das curvas de F0, nas modalidades frasais interrogativas e declarativas, para a variedade de Cametá, registraram menos variação intersilábica de F0, em relação a Mocajuba, indicando, portanto, essa variedade como tendo maior musicalidade, nos três tipos de acento lexical. Desta forma, apenas os resultados concernentes à variação melódica de F0 da variedade falada em Mocajuba assemelha-se com padrões entoacionais encontrados para outras regiões brasileiras, mais precisamente para o Norte e Nordeste brasileiro conforme descrito por Moraes (2003 apud SILVA e CUNHA, 2012, p. 10) e Silva e Cunha (2012). O parâmetro acústico de duração apresentou uma distinção dialetal significativa, posto que os dados de Cametá registraram sílabas mais longas, em relação a Mocajuba. A intensidade não apresentou variação significativa entre os dialetos estudados.

Palavras-chave: Descrição Prosódica; Projeto AMPER-POR; Análise Acústica.

Abstract: This work comprises a comparative study of previous prosodic descriptions from the varieties of Mocajuba and Cametá (PA) within the AMPER-POR project (COSTA, in progress). It aims to describe the intonation behavior of sentences in the neutral declarative and total interrogative modalities. The acoustic parameters of fundamental frequency (hereinafter F0), duration and intensity were the focus of analysis. The methodological procedures adopted were previously established by the AMPER-POR project (CRUZ et al., 2012). The melodic movements of the F0 curves, in the interrogative and declarative phrasal modalities, for the Cametá variety, registered less inter-syllabic variation of FO in relation to Mocajuba, indicating, therefore, this variety as having greater musicality in the three lexical accent types. Thus, only the results concerning the melodic F0 variation from the variety spoken in Mocajuba resembles intonation patterns found for other Brazilian regions, more precisely for the North and Northeast of Brazil as described by Moraes (2003 apud SILVA and CUNHA, 2012, p. 10) and Silva and Cunha (2012). The acoustic duration parameter presented a significant dialectal distinction, since Cametá data recorded longer syllables in relation to Mocajuba. The intensity did not present significant variation among the dialects studied. Keywords: Prosodic Description; AMPER-POR Project; Acoustic analysis.

Keywords: Prosodic Description; AMPER-POR project; Acoustic Analysis.

\section{Introdução}

A prosódia do Português Brasileiro $(\mathrm{PB})$ tem sido alvo de investigação recente pelo projeto AMPER-POR3, neste sentido, tem-se realizado estudos de natureza prosódica com análises pautadas na entoação de frases.

Por conseguinte, este artigo objetiva a descrição prosódica acústica de dados do projeto AMPER-POR para o estado do Pará, especialmente, em sentenças declarativas neutras e interrogativas totais do português falado em Cametá (PA) e Mocajuba (PA).

Para tanto, foi realizada uma análise interdialetal, a fim de caracterizar o padrão entoacional do falar cametaense e mocajubense por meio de três parâmetros acústicos:

\footnotetext{
${ }^{3}$ http://www.varialing.eu/
} 
Frequência Fundamental (medida em Hz), Duração (medida em ms) e Intensidade (medida em dB), a fim de responder questões, como: o padrão entoacional encontrado para as frases na modalidade declarativa neutra falada por locutores da cidade de Cametá é similar ao encontrado para Mocajuba? O padrão entoacional encontrado para as interrogativas da cidade de Cametá é semelhante ao encontrado para Mocajuba? Os padrões entoacionais encontrados para as declarativas neutras e interrogativas totais são os mesmos encontrados para outras regiões do país? Os parâmetros de duração (ms) e intensidade (dB) são fatores determinantes de distinção nas variedades em escopo?

Este artigo pauta-se na teoria da Sociofonética, uma ciência nova que possui por objeto de estudo a aglutinação de dois campos de investigação mais antigos, a Fonética e a Sociolinguística, como toda investigação conduzida no seio do projeto AMPER-POR. Isto posto, este trabalho trata das variações fonéticas acústicas e as características sociais dos falantes, como escolaridade e dialeto. Entre alguns teóricos que se encarregam deste estudo, cita-se: Foulkes e Scobbie e Watt (2010), Baranowski (2013) e Hay e Drager (2007 apud SORIANO, 2016).

A metodologia adotada é a mesma preestabelecida pelo projeto AMPER-POR4 (CRUZ et al., 2012) e para este estudo comparativo foram analisadas sentenças correspondentes as três pautas acentuais do Português: oxítona, paroxítona e proparoxítona, todas na fala de informante do sexo feminino, sendo o alvo da análise o último vocábulo do Sintagma Nominal Final de sentenças selecionadas previamente.

Em vistas gerais, este trabalho divide-se nas seguintes seções: Fundamentação Teórica (seção 1), em seguida, a descrição dos procedimentos metodológicos adotados para a concretização deste trabalho (seção 2), seguido da apresentação dos resultados (seção 3) e suas considerações finais.

\section{Fundamentação teórica}

Segundo Foulkes e Scobbie e Watt (2010), a palavra Sociofonética surgiu em 1974, na Dissertação de Deshaies-Lafontaine, a qual tratava sobre a variação do Francês canadense. O intuito da utilização do termo foi para demonstrar a conformidade entre as ciências Sociolinguística e Fonética em detrimento da Sintaxe ou do Léxico.

De acordo com Foulkes e Scobbie e Watt (2010), a Sociofonética é um campo de

\footnotetext{
${ }^{4}$ Atlas Prosódico Multimédia do Espaço Românico.
} 
investigação linguística que envolve a integração de princípios, técnicas e quadros teóricos da Fonética e da Sociolinguística, com a finalidade de explicar a variação social da fala.

Para Baranowski (2013), a Sociofonética é um instrumento que contribui para a compreensão da natureza da variação linguística e mudança, deste modo, é uma ciência que estuda como a língua falada varia de acordo com o contexto social em que ocorre, e como falantes e ouvintes são sensíveis a esta variação, portanto, está atrelada à produção e à percepção da fala em variação.

Como bem tem demonstrado estudos neste campo, a realização de qualquer palavra pode variar de acordo com o falante, o idioma, o contexto social, o tópico, o destinatário, a postura intencional tomada pelo orador, e inúmeros outros fatores. Neste contexto, a identidade linguística é construída simultaneamente a informações sociais, conforme explicita Soriano (2016).

Isto posto, a Fonética Acústica, que se encarrega de estudar aspectos físicos da produção da fala, tem demonstrado que o fenômeno da variação é um campo de estudo desta ciência e que estes fenômenos são provenientes, na maioria dos casos, não somente de fatores linguísticos, mas também de fatores sociais.

Este trabalho valeu-se da teoria da Sociofonética, exatamente por ser constituída de métodos baseados na Fonética Acústica e na Sociolinguística, haja vista a necessidade em considerar como fatores de análise, respectivamente, o parâmetro acústico fonético de F0 e fatores sociais, como procedência e escolaridade dos locutores entrevistados para se encontrar um padrão entoacional das localidades em escopo.

\section{Estudos geoprosódicos do PB}

Silva e Cunha (2012) caracterizaram o padrão entoacional de vinte e cinco capitais brasileiras. Para o trabalho intitulado "Caracterização prosódica dos falares brasileiros: a oração interrogativa total" que está vinculado ao projeto Atlas Linguístico do Brasil (ALiB), as autoras analisaram a variedade de cinco capitais: Teresina, João Pessoa, Maceió, Cuiabá e Florianópolis. As análises incidiram em sentenças na modalidade frasal, interrogativa total e procuraram responder, entre outras questões: 1) Quais são as implementações fonéticas dos acentos nucleares do sintagma entoacional da questão total nos falares das capitais brasileiras? 2) Qual é a distribuição geográfica dos padrões regionais da questão total no PB?

Para tanto, foram inquiridos quatro informantes não escolarizados por capital, distribuídos em duas faixas etárias 18 a 30 anos e 50 a 65 anos e nos dois sexos, feminino e 
masculino. Todos nascidos e criados na localidade pesquisada. O questionário aplicado segue o modelo do questionário fonético-fonológico (QFF) do ALiB.

As autoras afirmam que a diferença regional está principalmente no acento nuclear. Elas confirmam que o comportamento entoacional ascendente-descente no acento nuclear descrito por Moraes (2008) através da notação fonológica $L+H^{*} L \%$ está presente em praticamente todas as capitais brasileiras, com exceção de João Pessoa.

Um outro trabalho relevante que serviu para respaldar nossas análises foi o de Reis e Cunha (2012). As autoras estudaram o comportamento prosódico dialetal do português falado na capital de São Luis (MA) e no município de Brejo (MA). Suas análises foram substanciadas no campo da fonologia entoacional, entre os principais teóricos citados estão Sosa (1999), Cunha (2011) e Moraes (2003).

Alguns resultados encontrados para a caracterização entoacional do português brasileiro são citados pelas autoras, entre eles, o padrão entoacional para as declarativas, na região nuclear da sentença, relativo às variedades de Recife e Porto Alegre. Para Recife o movimento é identificado com um tom alto na sílaba pretônica, sofrendo uma descendência nas sílabas tônicas e postônicas. Por outro lado, para Porto Alegre, o movimento melódico inicia com tom alto na sílaba pretônica, espraiando-se até a sílaba tônica, para posteriormente sofrer descendência na postônica.

Reis e Cunha (2012, p. 11) afirmam que Moraes (2003) apresenta um notação para a modalidade interrogativa. A descrição do movimento de F0 registra uma subida melódica na sílaba pretônica até a sílaba tônica para posteriormente sofrer descendência na sílaba postônica final.

Os resultados relacionados a modalidade interrogativa no estudo realizado por Reis e Cunha (2012) registraram dois contornos melódicos, na região nuclear da sentença. Para a cidade de Brejo, o contorno melódico do último vocábulo da sentença inicia com um desenho de ascendência da sílaba pretônica até a sílaba tônica, mantendo-se com tom alto na postônica. Por outro lado, para São Luis, o movimento apresenta o desenho ascendente-descendente, com pico entoacional na sílaba tônica do vocábulo. Logo os resultados encontrados por Reis e Cunha (2012) para duas cidades do Maranhão registrou variação dialetal entoacional.

As pesquisas realizadas por Reis e Cunha (2012) e Silva e Cunha (2012) serviram para consubstanciar nosso trabalho, haja vista que se enquadram em estudos que também buscam descrever a variação entoacional, em várias regiões do Brasil. Para além, os resultados encontrados pelas autoras serviram para a interpretação de nossas análises no correspondente a variação melódica de F0 na variedade mocajubense. 


\section{Metodologia: formação e organização do corpus de Cametá (PA) e Mocajuba (PA)}

Adotaram-se, no presente estudo, todos os procedimentos metodológicos determinados pela coordenação geral do projeto AMPER-POR (CRUZ et al., 2012), e como um dos objetivos do projeto compreende uma análise contrastiva dos dialetos estudados, o corpus gravado é formado por seis repetições de 102 frases do corpus de base do projeto para a Língua Portuguesa. Cada um dos elementos constituintes das frases possui uma imagem correspondente, uma vez que não é permitido nenhum contato dos informantes com as frases escritas.

No momento da coleta de dados, a cada informante, foram pedidas seis repetições da série de frases do corpus (em ordem aleatória), ao todo, são geradas 612 repetições, sendo selecionadas para análise acústica as três melhores repetições, a fim de serem estabelecidas médias dos parâmetros acústicos: Frequência fundamental (em Hz), Duração (em ms) e Intensidade (em dB). Sintaticamente, as frases são montadas de forma a apresentar SujeitoVerbo-Complemento (SVC) e suas expansões com a inclusão de Sintagmas Preposicionais. Elas são concebidas de modo a contemplar as modalidades declarativa neutra e interrogativa total. Uma descrição mais detalhada da coleta dos dados, levantamento do corpus do trabalho e seleção dos informantes pode ser encontrada em Costa (2015, p. 54-58).

O material gravado passou, então, por seis etapas de tratamento: a) codificação; b) isolamento das repetições em arquivos de áudios individuais; c) aplicação do script lance_batch_easyalign_v3.praat para obter o textgrid dos arquivos .wav; d) segmentação fonética no programa PRAAT 6.0.39 por meio de um script de correção_segmentação.praat para $\begin{array}{lllll}\text { corrigir a } & \text { a } & \text { egmentação; } & \text { e) }\end{array}$ AMPER_Textgrid2Txt_V3_boucle_DepoisEasyAlign_v2.praat para gerar os arquivos com os parâmetros acústicos; f) seleção das três melhores repetições; g) rodadas no programa Matlab para se obter os arquivos fonos, estes que fornecem as médias de F0, duração e intensidade necessárias para o preenchimento das planilhas Excel e, consequentemente, para a feitura dos gráficos.

De posse dos arquivos fonos gerados em arquivos .TXT, procedeu-se à feitura dos gráficos no Excel. Para tanto, preencheu-se planilhas com as medidas dos parâmetros físicos analisados do último vocábulo da sentença, acompanhado da partícula "do", os quais estão 
distribuídos nos três tipos de acento lexical, respectivamente, proparoxítono: "do pássaro", paroxítono: "do Renato" e oxítono: "do bisavô", confrontando sempre a variável dialetal, em vocábulos declarativos e interrogativos. Os gráficos contendo as medidas de duração e intensidade foram montados, considerando, apenas, a média desses parâmetros na sílaba tônica dos vocábulos alvo, ou seja foram tomadas as medidas de duração e intensidade da sílaba 'pá' (v3) dos vocábulos proparoxítonos, da sílaba 'na' (v2) dos vocábulos paroxítonos e da sílaba 'vô' (v1) dos vocábulos oxítonos.

Foram selecionadas duas frases de cada pauta acentual, conforme apresentado no quadro 1.

\begin{tabular}{|c|c|c|}
\hline $\begin{array}{c}\text { QCENTUAÇÃO } \\
\text { (CÓDIGO/AMPER) }\end{array}$ & MOCAJUBA & CAMETÁ \\
\hline Oxítona (kwk) & O bisavô gosta do bisavô & O bisavô gosta do bisavô \\
\hline Oxítona (pwk) & O pássaro gosta do bisavô & O pássaro gosta do bisavô \\
\hline Paroxítona (kwt) & O bisavô gosta do Renato & O bisavô gosta do Renato \\
\hline Paroxítona (pwt) & O pássaro gosta de Renato & O pássaro gosta de Renato \\
\hline Proparoxítona (pwp) & O pássaro gosta do pássaro & O pássaro gosta do pássaro \\
\hline Proparoxítona (kwp) & O bisavô gosta do pássaro & O bisavô gosta do pássaro \\
\hline
\end{tabular}

Elaboração: Da autora, 2019

Desta maneira, foram analisadas as três melhores repetições de seis sentenças na modalidade declarativa neutra e seis na modalidade interrogativa total, na fala de seis locutores do sexo feminino, pertencentes as duas variedades em escopo, três mulheres de Mocajuba e três mulheres de Cametá, dos níveis fundamental, médio e superior de escolaridade, totalizando um corpus de 432 repetições.

A análise, como já mencionado, incidiu na variação dos parâmetros acústicos de F0, duração e intensidade - controlando o sintagma nominal final do enunciado. Foram calculadas 
as médias de cada parâmetro físico controlado. As frases escolhidas apresentam a mesma estrutura frasal, do tipo SVC, todas com dez vogais, e compostas por vocábulos proparoxítonos, paroxítonos e oxítonos que ocupam a posição de sujeito e complemento verbal (objeto).

\section{Análise e discussão dos resultados}

As análises respaldam-se no núcleo acentual do sintagma nominal final das frases, pelo qual se busca comparar as variáveis de procedência e incidiram na região nuclear da sentença, pois, como afirma Moraes (2008 apud SILVA; CUNHA, 2012), a identificação de uma frase interrogativa se dá pela movimento ascendente que ocorre, preferencialmente, no acento nuclear da frase fonológica, ou seja, no último vocábulo da sentença. As autoras ainda ressaltam a importância dessa subida melódica na distinção entre uma frase declarativa neutra e interrogativa total.

Para análise foi considerado o acento lexical tônico do vocábulo-alvo, que ora pode incidir na sílaba v3, se o vocábulo analisado for proparoxítono, pássaro; ora na sílaba v2, se o vocábulo analisado for paroxítono, Renato; e ora na sílaba v1, se o vocábulo analisado for oxítono, bisavô. Todos os vocábulos foram antecedidos pela partícula preposicional, "do" que ocupará sempre a posição, nos gráficos, de v4. As interpretações consideraram as sílabas adjacentes, pretônicas; e as subjacentes, postônicas às sílabas tônicas.

Nas figuras abaixo, lê-se o contorno prosódico encontrado para todas as frases de mesma estrutura acentual (tipo de acento) nas modalidades frasais alvo, a fileira de cima, representa sempre as frases declarativas neutras; e a fileira de baixo, as interrogativas totais. 
Figura 1 - Gráficos das variações de F0 nas quatro sílabas finais de enunciado por variedade: Cametá (azul) e Mocajuba (vermelho), em três tipos de acento lexical (respectivamente, proparoxítono, paroxítono e oxítono) e escolaridade fundamental
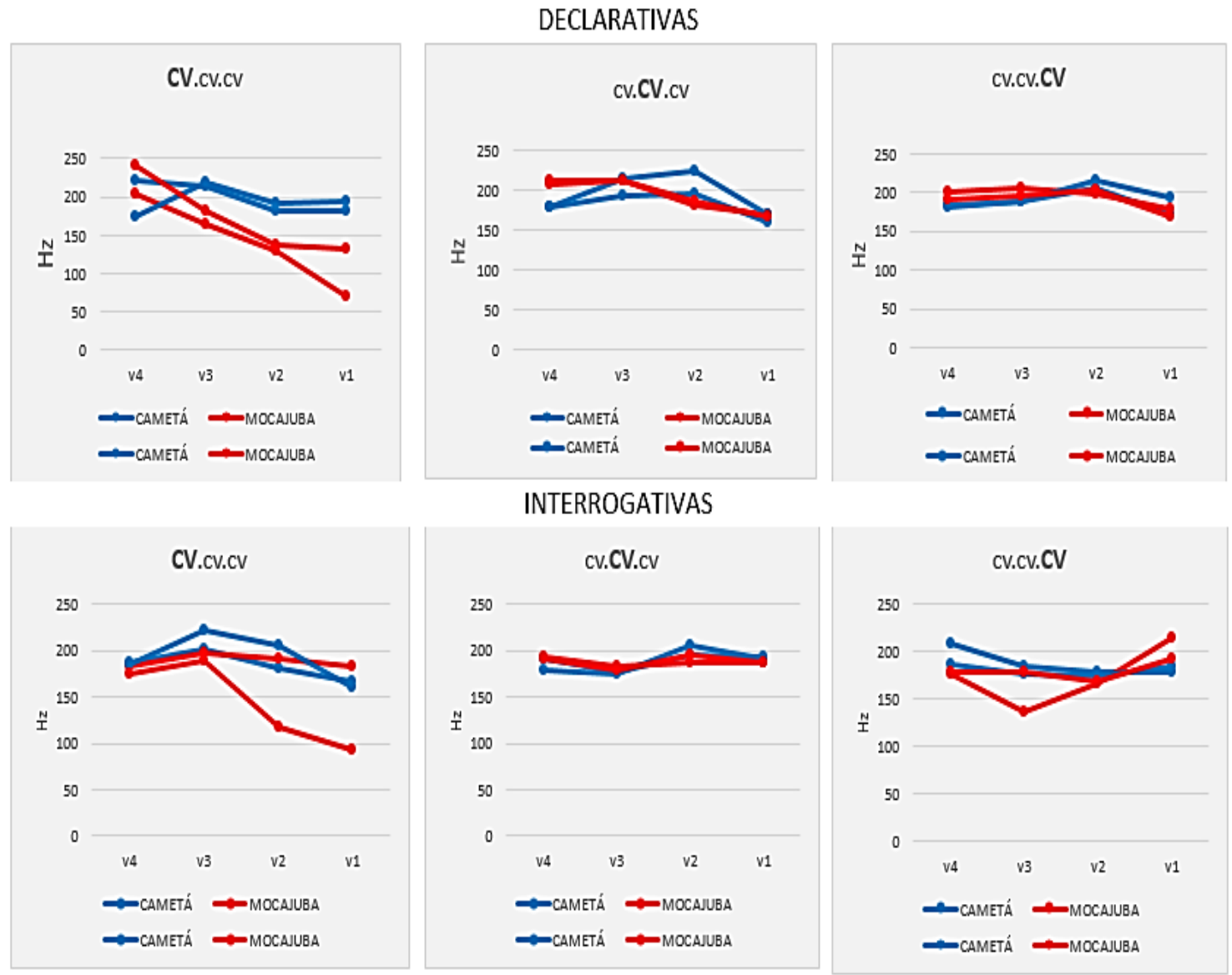

Legenda: Cv.cv.cv (proparoxítono), cv.Cv.cv (paroxítono) e cv.cv.Cv (oxítono)

Elaboração: Da autora, 2019

Conforme observado na figura acima, referentes aos dados dos locutores do nível mais baixo de escolaridade do corpus (Ensino Fundamental), os contornos melódicos de F0, nas duas variedades em estudo, apresentaram distinção melódica intersilábica, nas declarativas neutras proparoxítona e paroxítona (fileira superior), enquanto que nas interrogativas total (fileira inferior) o movimento diferenciou-se apenas nas oxítonas. O movimento de F0 significativo que estabelece a distinção das duas modalidades alvo, caracterizado como ascendente em enunciados interrogativos e descendente para os enunciados declarativos, ocorre justamente na 
sílaba tônica do vocábulo, independente do tipo de acento lexical, respectivamente, nas sílabas proparoxítonas (v3), paroxítonas (v2) e oxítonas (v1), apresentando uma maior inclinação das curvas melódicas de F0 na fala dos mocajubenses, nas duas modalidades em escopo.

Apesar de o pico maior de ascendência de F0, característico dos enunciados interrogativos, ocorrer na sílaba tônica de cada vocábulo, o movimento é "desenhado" na sílaba pretônica. Nas proparoxítonas acontece da sílaba pretônica v4 (do), registrando queda continua de F0 até a sílaba postônica final v1; nas paroxítonas na sílaba pretônica v3 (Re) e atingiu seu pico na sílaba tônica v2 (na), registrando queda de F0 na sílaba postônica v1 (to); e nas oxítonas na sílaba pretônica v2 (sa) com ascendência constante até a sílaba tônica v1 (vô).

Comportamento similar de F0 é registrado nas declarativas, uma vez que, também, é na sílaba pretônica que ocorre o pico de F0 necessário para antecipar o movimento de descendência de F0 característicos da entoação declarativa. Nos vocábulos proparoxítonos, o pico de F0 ocorre na sílaba pretônica v4 (do) para ocorrer a queda na sílaba tônica (pá); nas paroxítonas na sílaba pretônica v3 $(\mathrm{Re})$ e imediatamente vai caindo até a sílaba postônica v1 (to), nas oxítonas na sílaba pretônica v2 (sa) caindo até a sílaba tônica v1 (vô).

A variedade de Mocajuba acompanha a descrição prevista para as declarativas do PB, uma vez que o movimento melódico das curvas é o mesmo descrito por Moraes (2003 apud SILVA e CUNHA, 2012, p. 10) quando se refere as frases declarativas para o Português do Brasil, ao afirmar que as declarativas, de um modo geral, apresentam tom baixo na tônica que se espraia à postônica. 
Figura 2 - Gráficos das variações de F0 nas quatro sílabas finais de enunciado por variedade: Cametá (azul) e Mocajuba (vermelho), em três tipos de acento lexical, em três tipos de acento lexical (respectivamente, proparoxítono, paroxítono e oxítono) e escolaridade média
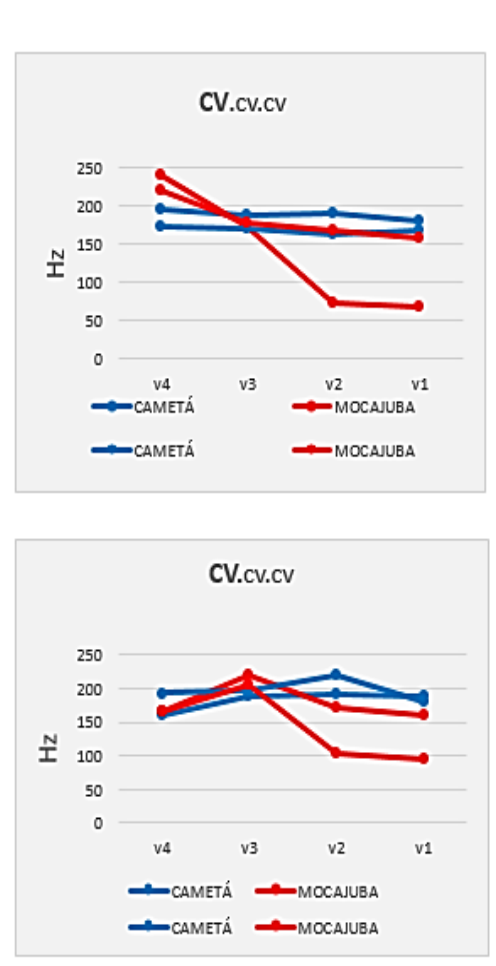

Legenda: Cv.cv.cv (proparoxítono), cv.Cv.cv (paroxítono) e cv.cv.Cv (oxítono)

Elaboração: Da autora, 2019

\section{DECLARATIVAS}

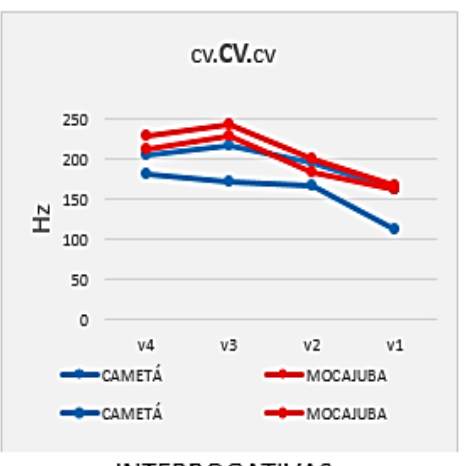

INTERROGATIVAS

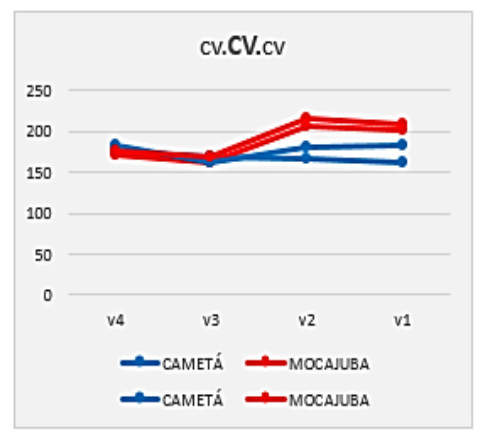

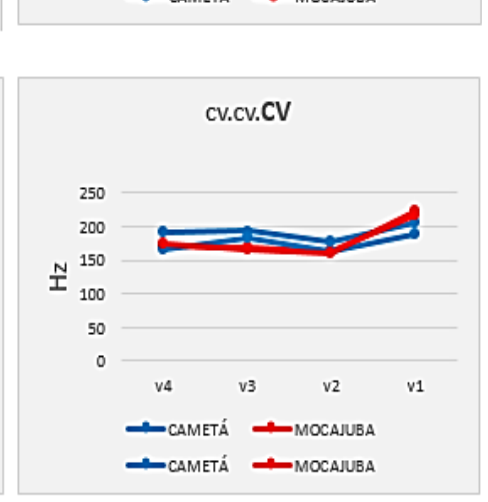

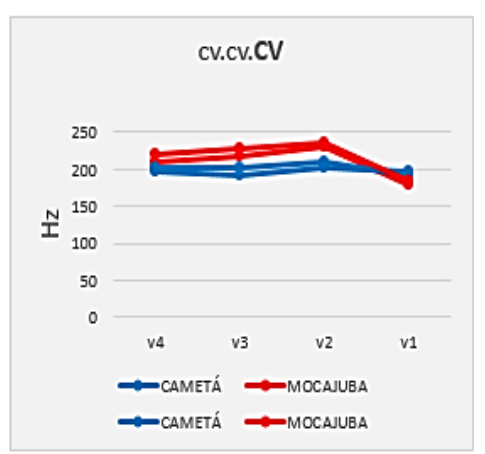

Nos gráficos correspondentes ao Ensino Médio, nota-se, que os contornos melódicos, das variedades em estudo, apresentam uma distinção do tipo de movimento de F0 nos vocábulos referentes às pautas acentuais proparoxítona, paroxítona e oxítona, nas declarativas. Para as interrogativas, observou-se essa variação nas proparoxítonas e paroxítonas. Apesar de em ambas as variedades o movimento distintivo de F0 ocorrer na sílaba tônica das duas modalidades alvo, caracterizando descendência nas declarativas e ascendência nas interrogativas, registram-se valores mais altos nas sílabas contendo o pico de F0 na variedade de Mocajuba.

Nas declarativas de Mocajuba, o movimento melódico inicia na sílaba pretônica de cada vocábulo, com movimento de descendência nas sílabas tônicas e postônicas, com a exceção das proparoxítonas, para as quais não foi possível encontrar um padrão entoacional. 
Nas paroxítonas a F0 atingiu seu pico máximo na sílaba pretônica v3 (Re) registrando uma queda melódica na sílaba tônica v2 (na); e nas oxítonas na sílaba pretônica v2 (sa) com ascendência constante até a sílaba tônica v1 (vô).

A descrição das curvas melódicas das frases interrogativas nas paroxítonas, assemelhase à feita por Silva e Cunha (2012) para a região Norte e Nordeste do Brasil, na qual ocorre uma subida melódica da F0 na sílaba tônica do acento nuclear, que se estende à postônica final, caracterizando um movimento ascendente nas interrogativas, o movimento foi melhor observado nas paroxítonas da variedade de Mocajuba.

Figura 3 - Gráficos das variações de F0 nas quatro sílabas finais de enunciado por variedade: Cametá (azul) e Mocajuba (vermelho), em três tipos de acento lexical (respectivamente, proparoxítono, paroxítono e oxítono) e escolaridade superior
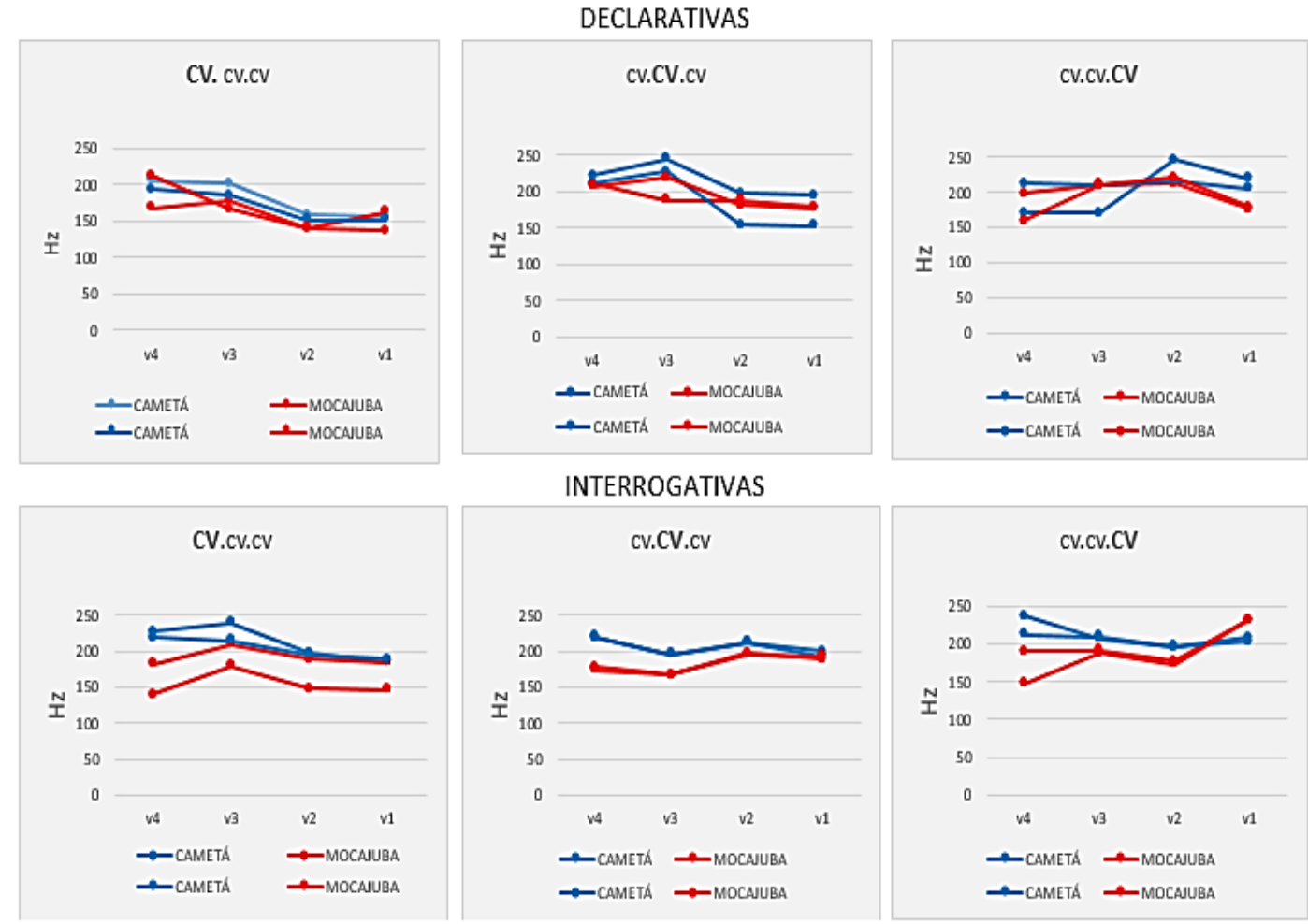

Legenda: Cv.cv.cv (proparoxítono), cv.Cv.cv (paroxítono) e cv.cv.Cv (oxítono) Elaboração: Da autora, 2019

Os contornos melódicos nos gráficos acima são correspondentes aos dados de fala das locutoras do Ensino Superior das variedades analisadas. Registrou-se um pico entoacional nas 
sílabas pretônicas, na modalidade frasal declarativa para os três tipos de acento lexical, respectivamente na sílaba v4 (do) para as proparoxítonas, nas paroxítonas na sílaba pretônica v3 (Re) e nas oxítonas na sílaba pretônica v2 (sa) para posteriormente ocorrer uma queda de F0 nas sílabas tônicas de cada vocábulo analisado. Para as interrogativas o pico entoacional aconteceu na sílaba tônica dos três tipos de acento analisado.

Para além, notou-se que houve uma distinção melódica em relação as variedades em escopo, posto que apenas Mocajuba apresentou movimentos característicos das curvas melódicas de F0, principalmente para as interrogativas, correspondentes aos resultados encontrados por Silva e Cunha (2012) como já mencionado. Notou-se movimentos mais discretos de FO para Cametá, não demonstrando variação significativa intersilábica nas três pautas acentuais.

Abaixo serão apresentadas as análises referentes à Duração, sendo confrontados os fatores escolaridade e variação dialetal.

Figura 4 - Gráficos das variações de Duração (ms) na sílaba tônica de vocábulos finais de enunciado por variedade: Cametá (azul) e Mocajuba (vermelho), em três tipos de acento lexical (respectivamente, proparoxítono, paroxítono e oxítono) nas três escolaridades analisadas
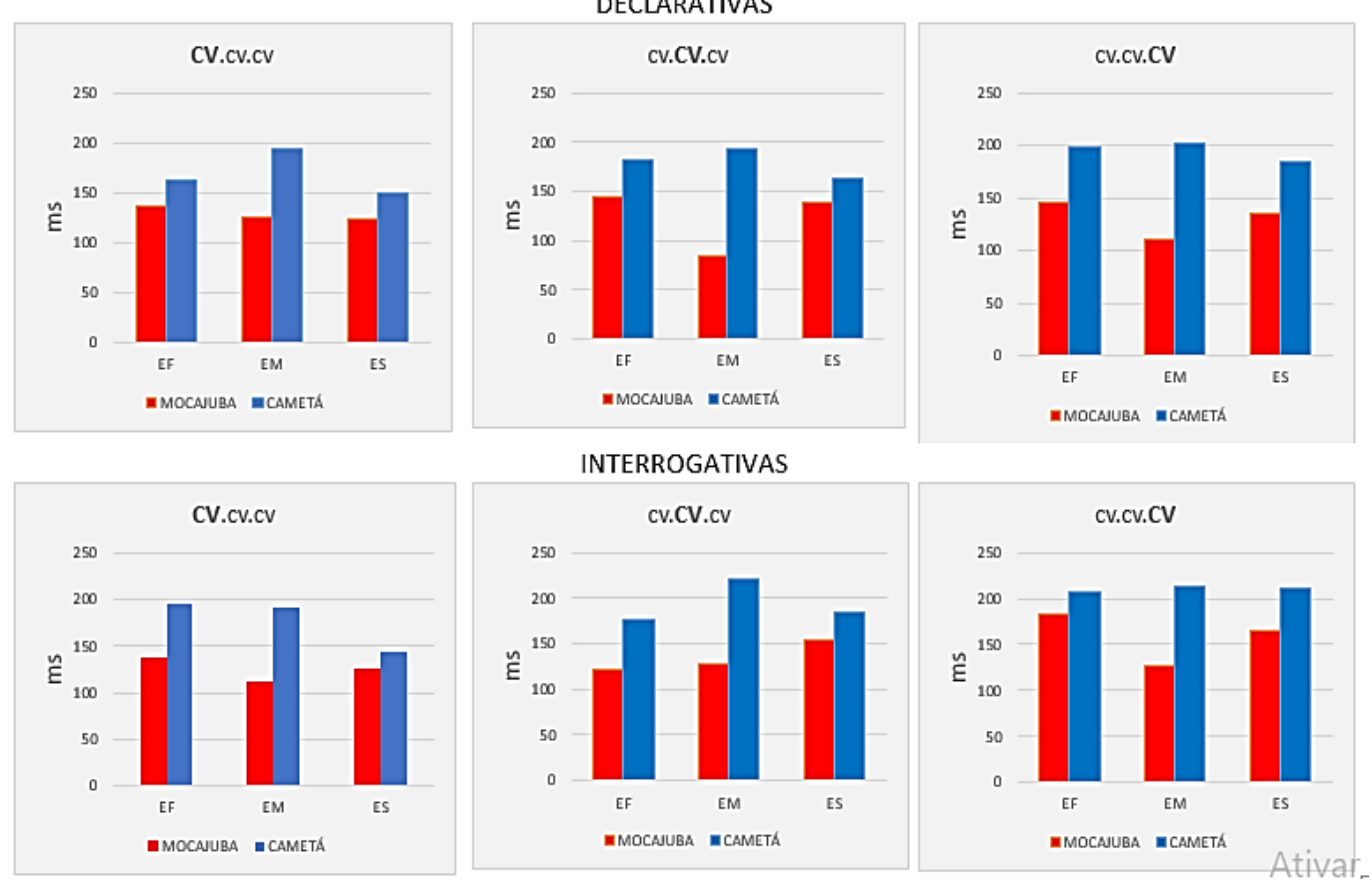

Legenda: Enunciados declarativos (fileira de cima) e interrogativos (fileira de baixo) e escolaridades Fundamental (EF), Médio (EM) e Superior (ES) Elaboração: Da autora, 2019 
Nos gráficos referentes ao parâmetro acústico Duração (medido em ms), notou-se que os níveis de tempo foram sempre mais elevados para a variedade falada em Cametá, enquanto Mocajuba manteve-se com níveis baixos de duração, o fenômeno ocorreu para as três pautas acentuais em estudo. Parecendo, portanto, a duração um parâmetro físico importante na caracterização dialetal das variedades em análise.

Figura 5 - Gráficos das variações de Intensidade $(\mathrm{dB})$ na sílaba tônica de vocábulos finais de enunciado por variedade: Cametá (azul) e Mocajuba (vermelho), em três tipos de acento lexical (respectivamente, proparoxítono, paroxítono e oxítono) nas três escolaridades analisadas
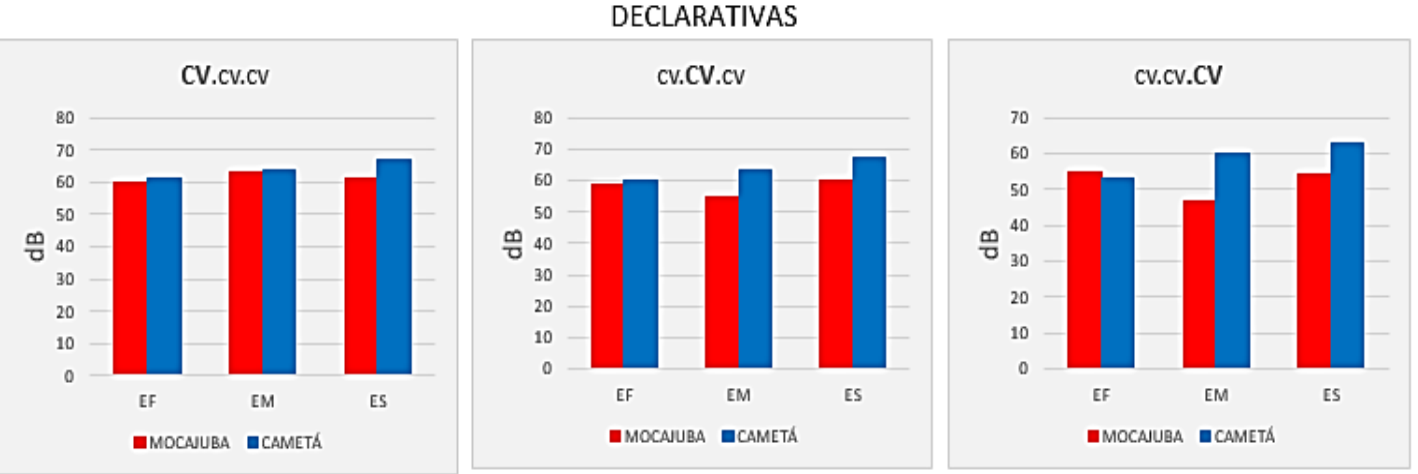

INTERROGATIVAS
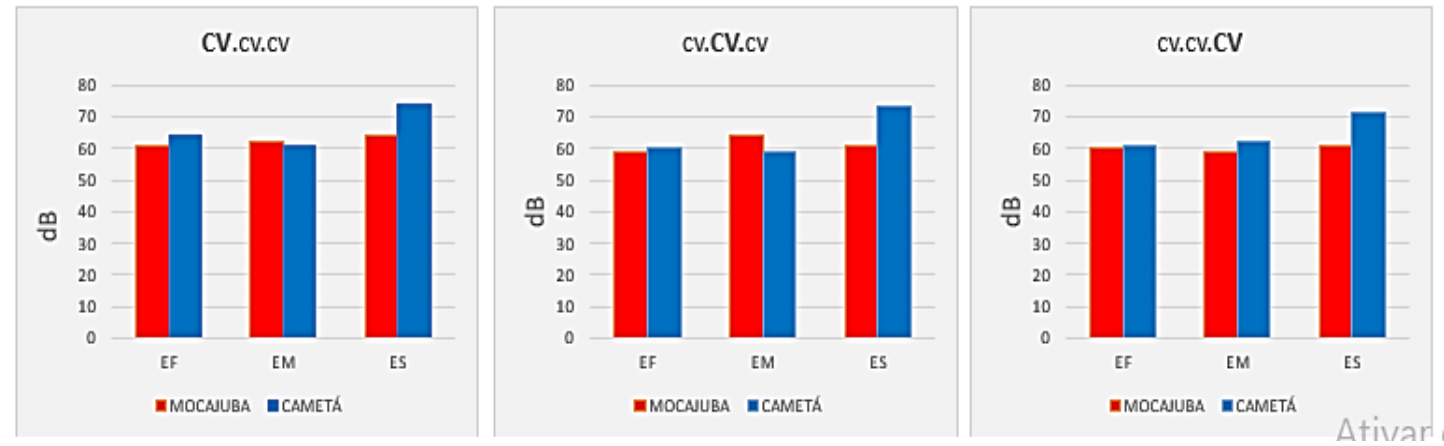

Legenda: Enunciados declarativos (fileira de cima) e interrogativos (fileira de baixo), escolaridades Fundamental (EF), Médio (EM) e Superior (ES)

Elaboração: Da autora, 2019

Uma análise dos gráficos concernentes ao parâmetro acústico de Intensidade (dB) demonstrou que não houve variação relevante de energia entre a fala dos locutores das variedades em estudo, haja vista que não houve uma diferença significativa entre os valores correspondentes à escolaridade e pauta acentual.

Como mencionado na introdução deste artigo, 4 eram as hipóteses a serem verificadas: 
a) se o padrão entoacional encontrado para as frases na modalidade declarativa neutra falada por locutores da cidade de Cametá é similar ao encontrado para Mocajuba; b) se o padrão entoacional encontrado para as interrogativas da cidade de Cametá é semelhante ao encontrado para Mocajuba; c) se os padrões entoacionais encontrados para as declarativas neutras e interrogativas totais são os mesmos encontrados para outras regiões do país e; d) se os parâmetros de duração (ms) e intensidade $(\mathrm{dB})$ são fatores determinantes de distinção nas variedades em escopo. Obtiveram-se as seguintes respostas:

a) O padrão entoacional encontrado para as frases na modalidade declarativa neutra, falada por locutores da cidade de Cametá não é similar ao encontrado para Mocajuba, pois para Cametá registrou-se pouca variação de movimento de F0 na formação do contorno entoacional, enquanto que os resultados de Mocajuba registraram uma variação significativa intersilábica configurando o movimento ascendente na pretônica e descendente na tônica encontrado por Moraes (2003 apud SILVA e CUNHA, 2012, p. 10) para descrever o português brasileiro;

b) O padrão entoacional encontrado para as interrogativas da cidade de Cametá não é semelhante ao encontrado para Mocajuba, uma vez que, os movimentos melódicos das curvas de F0 para Cametá registraram altura de F0 uniforme, nas sílabas, alvo de análise, não denotando variação significativa no que concerne a altura melódica, nos três níveis de escolaridade analisados. Por outro lado, Mocajuba registrou uma musicalidade na variação de F0, haja vista que apresentou variação entoacional intersilábica nos vocábulos das três pautas acentuais, principalmente nos níveis médio e superior de escolaridade;

c) Os padrões entoacionais encontrados para as interrogativas totais, da variedade de Mocajuba são os mesmos encontrados para a cidade de Brejo (MA) por Silva e Cunha (2012). As autoras descrevem que nas interrogativas há uma subida melódica da F0 na sílaba tônica do acento nuclear, que se estende à postônica final, caracterizando um movimento ascendente nas interrogativas, este movimento foi melhor observado nos resultados das paroxítonas de Mocajuba, nos três níveis de escolaridade;

d) As declarativas, referentes a variedade de Mocajuba, assemelham-se, ao padrão entoacinal encontrado por Reis e Cunha (2012) para as declarativas, na região nuclear da sentença, correspondente a variedade de Recife. O movimento é identificado com um tom alto na sílaba pretônica, sofrendo uma descendência nas sílabas tônicas e póstônicas. O movimento é observado nas três pautas acentuais e nos três níveis de 
escolaridade analisados;

e) O parâmetro de duração (ms) é um fator determinante de distinção nas variedades em escopo, posto que os dados de Cametá registraram uma variação de tempo que parece ser significativa em relação a Mocajuba, registrando, sempre, sílabas mais longas que as de Mocajuba;

f) O parâmetro de intensidade $(\mathrm{dB})$ não é um fator determinante de distinção nas variedades em escopo, posto que não houve variação de energia entre os dialetos estudados.

\section{Considerações finais}

Apresentaram-se aqui os resultados concernentes ao estudo entoacional da fala de duas variedades do estado do Pará, a cametaense e a mocajubense, resultado de descrição e análise acústica.

Uma observação minuciosa das curvas melódicas referentes à F0 da sílaba tônica do último vocábulo das sentenças em escopo, nas três pautas acentuais do português (proparoxítona, paroxítona e oxítona) e nas duas modalidades frasais, declarativa neutra e interrogativa total, denotou distinção entoacional relevante, que ocorre na sílaba pretônica e tônica dos vocábulos analisados. Notou-se, claramente, para a variedade de Cametá a presença de curvas com pouca diferença de inclinação de F0 intersilábica. O comportamento "monotônico" das curvas melódicas de F0 encontrado para Cametá será ponto de investigação para os próximos estudos, posto que a causa desse comportamento, talvez seja a influência de algum substrato linguístico.

O parâmetro acústico de Duração denotou maior duração de tempo na fala dos locutores do Cametá, o fenômeno incidiu nos vocábulos correspondentes as três pautas acentuais, já a Intensidade não demonstrou variação significativa. Nesse sentido, estas considerações contribuem para a caracterização prosódica do falar na Amazônia.

\section{Referências}

BARANOWSKI, M. Sociophonetics. In: BAYLEY, Robert; CAMERON, Richard; LUCAS, Ceil (eds.). The Oxford handbook of sociolinguistics. Oxford: Oxford University Press, 2013. p.403-424. 
COSTA, Maria Sebastiana Silva. Estudo comparativo e perceptual do português falado na Amazônia: a influência da LGA nos dialetos amazônicos. Tese (Doutorado em Letras) - UFPA/ILC/PPGL, Belém, Em andamento.

Análise acústica da relação acento versus entoação no português falado em Mocajuba: contribuições para o projeto AMPER Norte. 2015. 150 f. Dissertação (Mestrado em Letras) - UFPA/ILC/CML, Belém, 2015.

CRUZ, Regina et al. Formação e Anotação do Corpus do Projeto AMPER Norte. In: Proceedings of GSCP 2012, Belo Horizonte: UFMG, fevereiro de 2012.

FOULKES, Paul; SCOBBIE, James; WATT, Dominic. Sociophonetics. In: HARDCASTLE, W.; LAVER, J.; GIBBON, F. (Orgs.). The handbook of Phonetic Sciences. Oxford: Wiley-Blackwell, 2010.

REIS, Gizelly, F. M.; CUNHA, Cláudia de Souza. Enunciados assertivos e interrogativos na prosódia maranhense: resultados preliminares. Revista Littera Online, Maranhão, №. 5, p. 7-22, 2012.

SILVA, Joelma Castelo Branco; CUNHA, Cláudia de Souza. Caracterização prosódica dos falares brasileiros: A oração interrogativa total. Revista do GELNE, Natal, v. 14, p. 59-75, 2012.

SORIANO, Larissa Grasiela M. Percepções sociofonéticas do (-R) em São Paulo. 2016. 137 f. Dissertação (Mestrado em Letras). Faculdade de Filosofia, Letras e Ciências Humanas, Universidade de São Paulo, São Paulo. 